\title{
Yagi-Ude Antenna AS WiFi Electromagnetic SoUrCe
}

\author{
Rene Hartansky, Martin Mierka \& Marek Vimpel
}
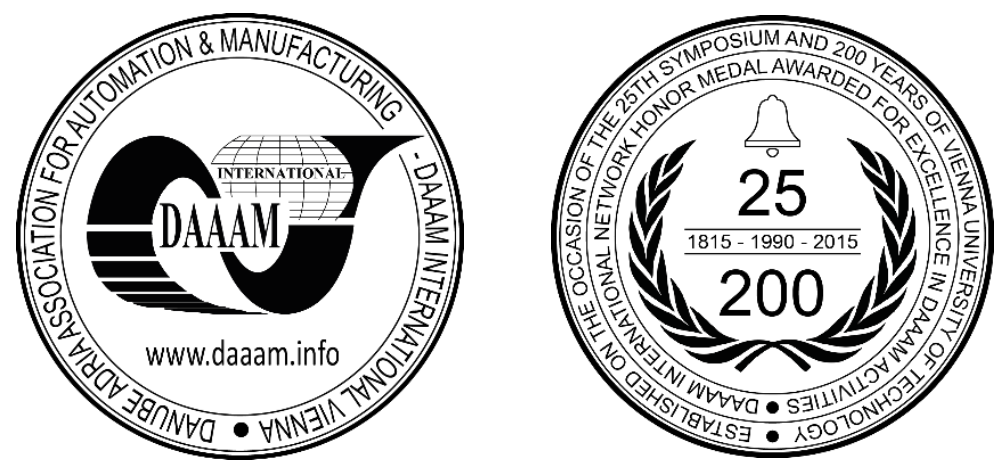

This Publication has to be referred as: Hartansky, R[ene]; Mierka, M[artin] \& Vimpel, M[arek] (2016). Yagi-Ude Antenna as WiFi Electromagnetic Source, Proceedings of the 27th DAAAM International Symposium, pp.0730-0733, B. Katalinic (Ed.), Published by DAAAM International, ISBN 978-3-902734-08-2, ISSN 1726-9679, Vienna, Austria DOI: $10.2507 / 27$ th.daaam.proceedings.105

\begin{abstract}
There are a lot of applications that require signal transmission in high-frequency spectrum (e.g. data and sensor networks), because of that we need to build up a set of equipment that allows this transmission. In this article we will occupy with the design of electromagnetic (EM) field radiator, whose task is to create EM field and capture information from MEMS structure. In this case the EM field is influenced by the MEMS structure so, that the EM field is carrying information about processes happening in MEMS.
\end{abstract}

Keywords: Electromagnetic field; Antennas, Method of moment; Gain; VSWR.

\section{Introduction}

The article deals with Yagi's antenna design in range of $2.4 \mathrm{GHz}$, which will have significant polarizing properties and gain minimally $12 \mathrm{dBi}$ in range from $2.4 \mathrm{GHz}$ to $2.5 \mathrm{GHz}$. In the design process of the antenna has been taken to minimize the cross-polarization and maximize gain front-back ratio. In this case the transferring signals in sensor (sensor network) environment, the interference from another signal sources will be minimized [1]. Another reason is the fact that the useful signals are in range from $2.4 \mathrm{GHz}$ to $2.5 \mathrm{GHz}$ [2]. It means that the Yagi's antenna has to be relatively wide ranged (this must be valid especially for its radiation pattern) however the higher priority is, that the antennas input impedance has to be constant. By using a typical coaxial cable of $50 \Omega$ the input impedance has to be around $200 \Omega$ and its imaginary component has to be nearly zero. The computation and design of antenna was conducted by recomputing the tabular parameters from other Yagi and Ude works. However, this way designed antenna had not adequate parameters [3]. Because of this, a new computation based on moment method in FEKO software, has been done. The basic geometry of Yagi's antenna was put into the computer software. The more useful shape of radiation patter was found by moving the antenna elements. The result is antenna geometry, where the radiation patterns in above mentioned range are almost identical. The results presented in further are completed also by graphs. The next solved task is stabilizing the input impedance. This has been solved by changing the shape of scatter and also by changing size and distance of first director. More about this task you can find further in this article completed with a lot of graphs showing positive results. 


\section{Finding the geometry of Yagi antenna}

We can say, that Yagi-Ude antenna seems to be very simple. In spite of this, the design of such an antenna is complicated and takes too long. There are two ways how to find a solution:

1. The Yagi and Ude theory gives us the possibility to design the structure and number of antenna components (directors). These components will ensure us quite enough antenna gain however, no radiation patterns and input impedance characteristics are obtained. Finally it is necessary to measure the antenna and correct the components sizes.

2. It is also possible to use an existing antenna with adequate gain and good shape of radiation pattern to adapt it to the given frequency range.

Comparing these two procedures, the first one is more complicated and time consuming than the second one. According to [4] the geometry of seven component antenna has been chosen and modified for frequency $2.5 \mathrm{GHz}$. The antenna components sizes are in Table 1.

\begin{tabular}{|c|c|c|c|c|c|c|c|}
\hline & $\begin{array}{c}\text { Reflector } \\
{[\mathbf{m m}]}\end{array}$ & $\begin{array}{c}\text { Scatter } \\
{[\mathbf{m m}]}\end{array}$ & $\begin{array}{c}\text { 1. Dir. } \\
{[\mathbf{m m}]}\end{array}$ & $\begin{array}{c}\text { 2. Dir. } \\
{[\mathbf{m m}]}\end{array}$ & $\begin{array}{c}\text { 3. Dir. } \\
{[\mathbf{m m}]}\end{array}$ & $\begin{array}{c}\text { 4. Dir. } \\
{[\mathbf{m m}]}\end{array}$ & $\begin{array}{c}\text { 5. Dir. } \\
{[\mathbf{m m}]}\end{array}$ \\
\hline Length & 57.1 & 62.4 & 56.4 & 52.3 & 51.6 & 52.8 & 51.6 \\
\hline Distance & -30.0 & 0.0 & 6.0 & 40.6 & 89.4 & 128.1 & 178.8 \\
\hline Perimeter & 0.4 & 0.4 & 0.4 & 0.4 & 0.4 & 0.4 & 0.4 \\
\hline
\end{tabular}

Table 1. Antenna components dimensions

To simulate the radiation of our antenna, computer package FEKO has been used. More detailed description can be found in [3]. The results are radiation patterns in $\mathrm{E}$ and $\mathrm{H}$ plane (Fig. 1).
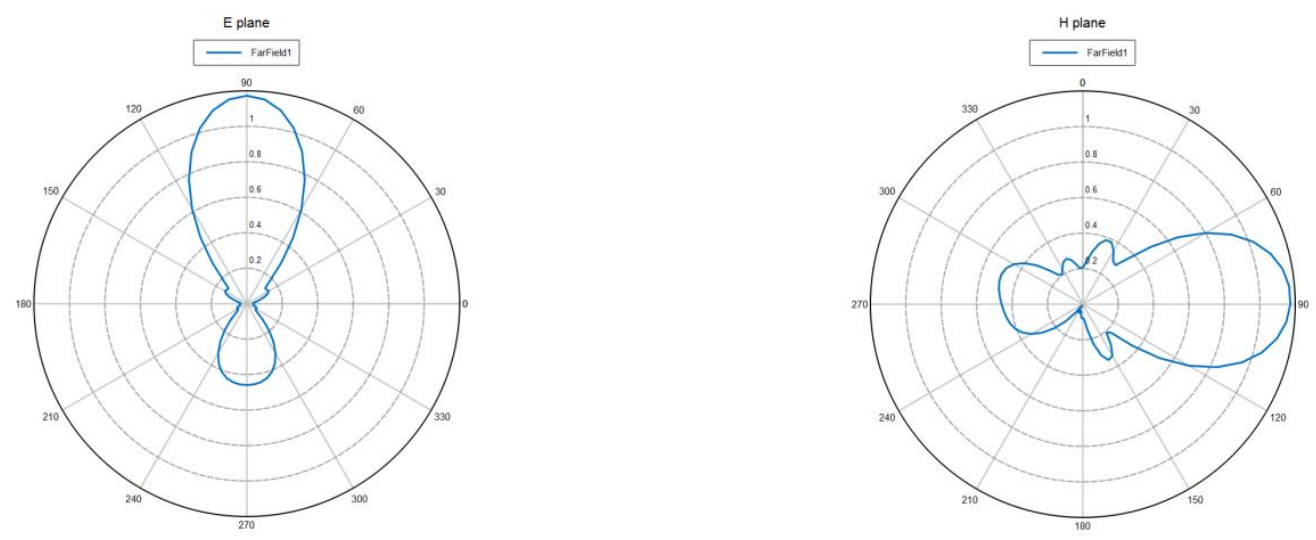

Fig. 1. Radiation pattern of designed antenna (E plane and $\mathrm{H}$ plane)

As can be seen from radiation pattern of Yagi antenna it's scattering into the back direction is very large. This means, that when we are transporting the signal, not only direct signal is being received, but also the reflected one, what leads to increased error rate of transmitted data. The designed antenna in this shape is unsatisfying for data signals transfer.

\section{Antenna optimizing design}

Because of the previous results, the antenna design has to be made by a different way as usual. The antenna must have an aligned input impedance and prescribed gain in wide frequency range. This leads to use large diameter directors. The used components have diameter equal to $6 \mathrm{~mm}$. It's also known, that the first director is used as matching one (matches the input impedance to characteristic impedance of feeder). This director does not influence neither the shape of radiation pattern nor gain of antenna [4]. So the beginning of Yagi antenna design is without matching director.

Firstly, the approximate length of half-wave dipole will be computed (this will be used to feed the antenna):

$$
l \doteq \frac{\lambda}{2}=\frac{c}{2 f}=\frac{310^{8}}{22.510^{9}}=6 \mathrm{~cm}
$$

According to [4], distance between director and reflector from radiator must be less than 0.41 , length of reflector is greater than the length of radiator (scatter element) and length of director shorter than the length of radiator. These conditions had to be set at the beginning of the simulation process of Yagi antenna. Components have been set into the FEKO 
environment and the system had been enlarged step by step [5]. All sizes and distances have been chosen in such a way, that the gain of antenna should be as high as possible (for given number of components). Next component has been added only when the used were tuned to maximal gain. The last director was not added to get a higher gain, but to change the radiation pattern, especially to change (maximize) the front-back ratio.

You can find the dimension results in Table 2.

\begin{tabular}{|c|c|c|c|c|c|c|c|c|c|}
\hline & $\begin{array}{c}\text { Refl. } \\
{[\mathbf{m m}]}\end{array}$ & $\begin{array}{c}\text { Scat. } \\
{[\mathbf{m m}]}\end{array}$ & $\begin{array}{c}\mathbf{1 . ~ D i r .} \\
{[\mathbf{m m}]}\end{array}$ & $\begin{array}{c}\text { 2. Dir. } \\
{[\mathbf{m m}]}\end{array}$ & $\begin{array}{c}\text { 3. Dir. } \\
{[\mathbf{m m}]}\end{array}$ & $\begin{array}{c}\text { 4. Dir. } \\
{[\mathbf{m m}]}\end{array}$ & $\begin{array}{c}\text { 5. Dir. } \\
{[\mathbf{m m}]}\end{array}$ & $\begin{array}{c}\text { 6. Dir. } \\
{[\mathbf{m m}]}\end{array}$ & $\begin{array}{c}\text { 7. Dir. } \\
{[\mathbf{m m}]}\end{array}$ \\
\hline Length & 61 & 58 & 50 & 47 & 45 & 43 & 42 & 42 & 42 \\
\hline Distance & -30.5 & 0.0 & 17.5 & 51.5 & 83.0 & 105.0 & 142.1 & 179.5 & 238.0 \\
\hline Perimeter & 3 & 3 & 3 & 3 & 3 & 3 & 3 & 3 & 3 \\
\hline
\end{tabular}

Table 2. Front-back optimizing antenna components dimensions

Radiation patterns of this antenna can be seen in Fig. 2.
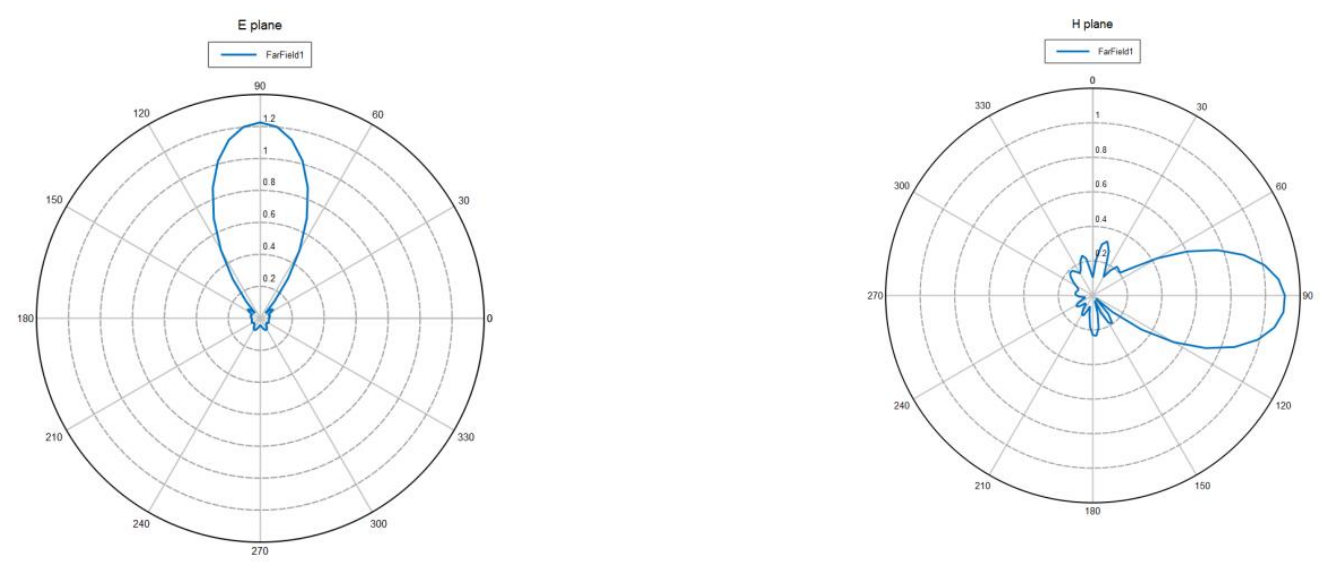

Fig. 2. Radiation pattern of optimized antenna (E plane and $\mathrm{H}$ plane)

\section{Antenna optimizing input impedance}

Two requests of Yagi antenna design were fulfilled till now (design for maximal gain and design for maximal front-back ratio of radiation pattern). The value of input impedance and its dependency on frequency (in frequency range from 2.4 to $2.5 \mathrm{GHz}$ ) has still to be made. According to [6], [7], the input impedance can be influenced by following three factors:

1. adding a matching director

2. changing the shape and size of scatter

3. changing the length of reflector.

These changes result using a nine component antenna can be found in Fig. 3.

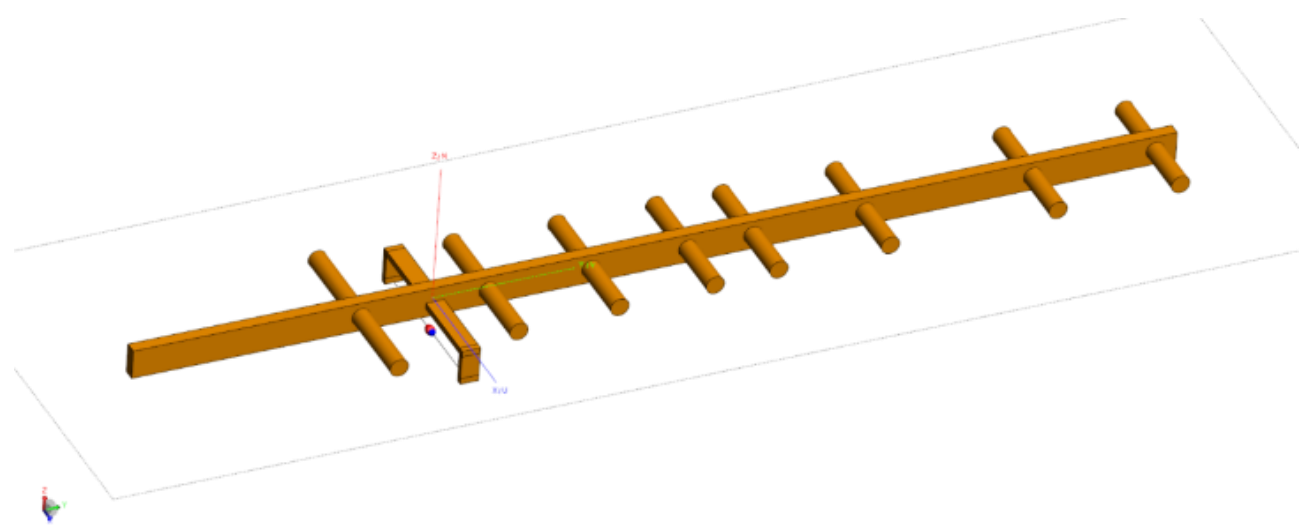

Fig. 3. Model of manufactured $12 \mathrm{~dB}$ antenna

Feeding the antenna with $50 \Omega$ coaxial wire with an symmetrical loop at the end gives us a very good ratio of standing wave VSWR in wide frequency range. This can be seen in Fig. 4. 


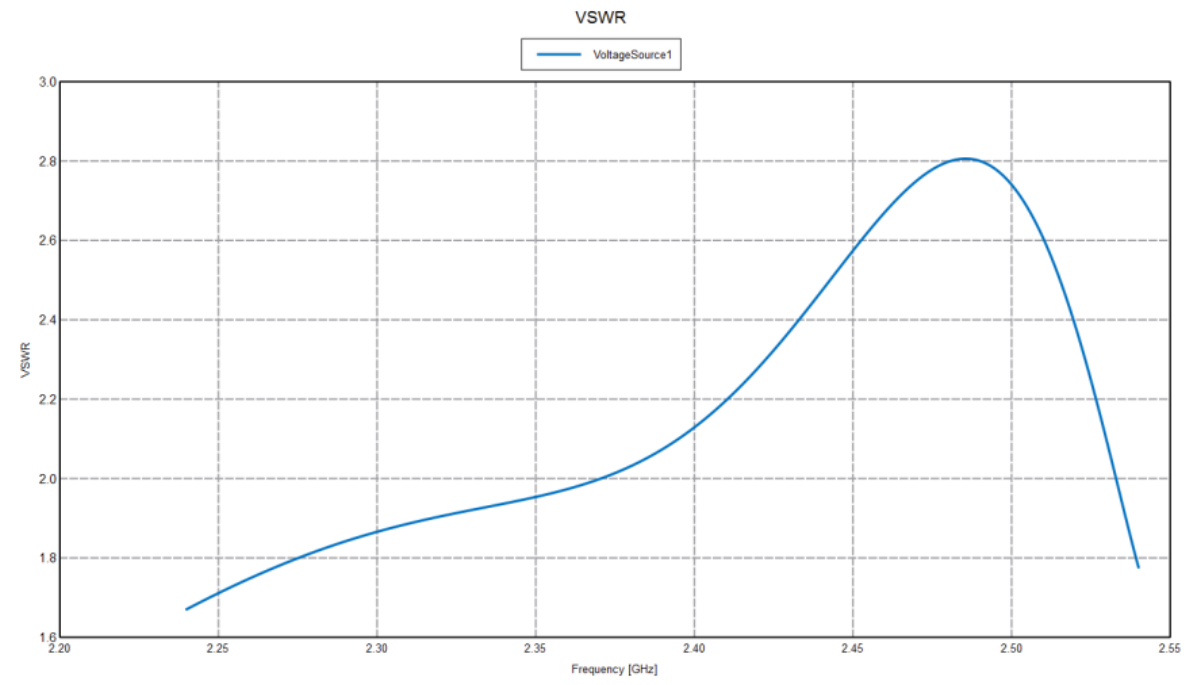

Fig. 4. Model of manufactured $12 \mathrm{~dB}$ antenna

\section{Conclusion}

The point of this article is to give us instruction for analysis and synthesis more component Yagi-Ude antenna by fulfilling the input parameter requirements. We have focused on fulfilling the direction characteristics, better said maximum gain and maximum radiated power - minimalization VSWR [8]. Such proposed antenna will be used as source of electromagnetic field by solving project APVV-14-0076.

\section{Acknowledgments}

This work was supported by the project APVV-14-0076.

\section{References}

[1] Farkas, P., Michalovic, M., Majchrak, S. \& Rakus, M. (2009) One Experiment with Wireless Sensor Network. TSP 2009 Telecommunications and Signal Processing : 32nd International Conference. Dunakiliti, Hungary, 26.27.8.2009. Budapest : Asszisztencia Szervezö Kft., 2009, pp. CD-Rom. ISBN: 978-963-06-7716-5.

[2] Kenyeres, J., Sajban, S., Farkas, P. \& Rakus, M. (2010) Indoor Experiment with WSN Application. MIPRO 2010 : 33rd International Convention. Conference: Computers in Education. Opatija, Croatia, 24.-28.5.2010. Rijeka : Croatian Society for Information and Communication Technology, Electronics and Microelectronics - MIPRO, 2010, pp.863-866. ISBN: 978-953-233-054-0.

[3] Bittera, M. \& Smiesko, V. (2012) Directivity Error of Broadband Antennas at EMI Measurement. Przeglad elektrotechniczny. Vol. 88, No. 6, 2012, pp.61-63., ISSN: 0033-2097.

[4] Kraus, D. J.: Antennas, McGRAW-HILL, ISBN: 0-07-100482-3.

[5] Bozek, P. \& Turygin, Y. (2014) Measurement of the operating parameters and numerical analysis of the mechanical subsystem. Measurement Science Review. Vol. 14, No. 4, pp. 198-203, ISSN: 1335-8871.

[6] Hallon, J. \& Kovac, K. (2013) Simplified generation of electromagnetic field within EMC immunity test area. Procedia Engineering: 24th DAAAM international symposium on intelligent manufacturing and automation. Zadar, Croatia, 23-26th October 2013, 69. pp. 27-34. ISSN: 1877-7058.

[7] Bittera, M., Smiesko, V., Kovac, K. \& Hallon, J. (2010) Directional Properties of the Bilog Antenna as a Source of Radiated Electromagnetic Interference Measurement Uncertainty. IET Microwaves Antennas \& Propagation. Vol. 4, Iss. 10, 2010, pp. 1469-1474. ISSN: 1751-8725.

[8] Hallon, J., Kovac, K. \& Szolik, I. (2006) Geometrical Configuration of Cabling as Factor Influencing the Reproducibility of EMC Imunity Tests. Radioengineering. Vol. 15, No. 4, 2006, pp. 73-33. ISSN: 1210-2512. 